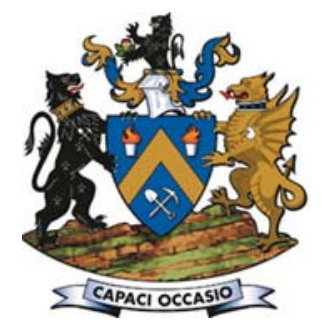

\title{
NaOH-assisted direct reduction of Ring of Fire chromite ores, and the associated implications for processing
}

\author{
by S. Sokhanvaran*, D. Paktunc*, and A. Barnes ${ }^{\dagger}$
}

\section{Synopsis}

As part of a broader programme to fully characterize the chromite ores discovered in the 'Ring of Fire' region of northern Ontario, NRCan and private research facilities in Canada have performed extensive test work over the past six years. The studies focused on developing alternative approaches for producing ferrochrome at lower temperatures and with fewer greenhouse gas emissions. The use of various fluxes or catalysts for accelerated direct reduction had yielded promising results, particularly with caustic soda $(\mathrm{NaOH})$. The initial work had been protected by a patent known as the 'KWG process'. The most recent work by NRCan has confirmed that the addition of $\mathrm{NaOH}$ to chromite ores in carefully controlled amounts leads to high degrees of metallization at much lower temperatures than would be achieved by conventional smelting technologies, at greatly accelerated reactions rates.

This paper summarizes the key findings of the latest work, including the role of $\mathrm{NaOH}$ in the reduction process and parameters influencing the degree of metallization and alloy particle growth. The paper will also discuss the implications of the results with respect to benefits, challenges, and opportunities for processing Ring of Fire chromite ores into saleable chrome units.

\section{Keywords}

chromite, ferrochrome, prereduction, direct reduction, catalysts, Ring of Fire.

\section{Introduction}

Chromium is one of the essential commodities for today's life, with applications in stainless and high-alloy steels, providing enhanced corrosion resistance and improved mechanical properties. Chromium is usually added to the steel in the form of ferrochrome (FeCr) alloy. The 'Ring of Fire' chromite deposit in northern Ontario presents an opportunity for Canada to enter the globally strategic market. It contains the only commercial quantities of chromite in North America and is the fourth largest deposit in the world. The resources, including Measured, Indicated, and Inferred, are $300 \mathrm{Mt}$ grading approximately $33 \% \mathrm{Cr}_{2} \mathrm{O}_{3}$. However, the remote location of the deposits makes development challenging. The preference for processing the chromite ore to marketable ferrochromium alloy within Ontario constitutes an additional challenge due to high electricity costs.

Currently, $80 \%$ of the world's FeCr is produced in submerged arc furnaces. There are four technologies currently used for the production of ferrochrome alloys. These are the conventional semi-closed furnace, the Outotec process, the DC arc furnace, and the Premus process. Disadvantages of the smelting processes include high energy consumption, between about 3.4 and 4.6 MWh per ton of ferrochrome produced (Ugwuegbu, 2012; Cramer, 2016), and generation of greenhouse gas emissions as high as $1 \mathrm{t}$ of $\mathrm{CO}_{2}$ per ton of ferrochrome produced. Under current market conditions with oversupply of FeCr (Kelly and Matos, 2014), production of ferrochrome at a competitive cost is a key factor if Canada is to enter this market. This requires either optimization of current processes or development of new processes that require less energy and can operate with a smaller environmental footprint.

The Premus (Naicker, 2006) technology has the lowest specific electrical energy consumption but it has a slightly larger carbon footprint. The raw materials, including chromite ore, reductants, and clay binder are milled, pelletized, indurated, and fed to a rotary kiln where they are partially prereduced. The hot, prereduced, and sintered pellets are then charged into closed submerged arc furnaces. Prereduction of the pellets in addition to charging them hot reduces the overall amount of electrical energy needed for ferrochrome production.

Processes that maximize the extent of solid-state prereduction hold the best potential to reduce overall specific electrical energy consumption. The use of additives to enhance reduction kinetics has been extensively studied. In cases where the reaction is controlled by diffusion of ions, fluxing agents can enhance the rate of reaction by forming a liquid layer around chromite grains to enable

* Canmet Mining, Canada.

$+*$ Metallurgical Process Consultants Ltd, Canada.

(c) The Southern African Institute of Mining and Metallurgy, 2018. ISSN 2225-6253. This paper was first presented at the INFACON XV:

International Ferro-Alloys Congress, 25-28

February 2018, Century City Conference Centre and Hotel, Cape Town, South Africa 


\section{Na0H-assisted direct reduction of Ring of Fire chromite ores}

faster diffusion or transport of the reducible ions. The presence of flux on the surface of chromite during all stages of reduction provides an enhanced access to $\mathrm{Cr}$ and $\mathrm{Fe}$ oxides remaining in the shrinking core of chromite and enables the reduction reactions to continue (Dawson and Edwards, 1986).

The influence of various fluxing agents on the direct reduction of chromite has been extensively investigated by numerous researchers. The list of additives includes halides (Dawson and Edwards, 1986; Katayama, Tokuda, and Ohtani 1985; Li et al. 2011), hydroxides (Winter, 2015), carbonates (van Deventer, 1988; Neizel et al., 2013), oxides (Sudar Murti et al., 1983; van Deventer, 1988; Neuschutz et al., 1995; Ding, 1997; Ding and Warner, 1997; Lekatou and Walker, 1997; Weber and Eric, 2006; Wang, Wang, and Chou, 2015), and borates (Bisaka, Makwarela, and Erwee, 2016; Lu, 2012; Katayama, Tokuda, and Ohtani, 1985). Borate was reported to be the most effective additive among other available options (Katayama, Tokuda, and Ohtani, 1985; Li et al., 2011).

Work performed in South Africa by Barnes, Finn, and Algie (1983) on the prereduction of UG2 chromites, and early TGA testing of the Ring of Fire ores indicated that a prereduction route was worth investigating for the Canadian ores. In 2013, based on the improvements seen with UG2 ores, prereduction test work involving the use of small amounts of alkali salts was conducted on the Ring of Fire chromites. Results from small-scale TGA tests in a Netsch TGA/DSC/MS were particularly encouraging, with dramatic improvements in both the reaction rates and extent of reduction at temperature compared to uncatalysed ores, as well as lower temperatures for the onset of reduction (Barnes, Muinonen, and Lavigne, 2015)

Natural Resources Canada (NRCan) has been directed through Budget 2015 to provide significant support for the development of methods for direct reduction of chromite using various fluxes or catalysts. Part of this study is focused on the effective role of caustic soda $(\mathrm{NaOH})$ in direct reduction. The initial work has been protected by a patent application for the 'KWG process'(Barnes, Muinonen, and Lavigne, 2015; Winter, 2015). Further investigations by NRCan confirmed that the addition of $\mathrm{NaOH}$ to chromite ores led to accelerated reaction rates and high degrees of metallization at lower temperatures than would be achieved by conventional smelting technologies. Carbothermic reactions referred to in this paper involved combinations of $\mathrm{NaOH}$, chromite, and carbon under an argon atmosphere.

\section{Experimental approach}

The ore and concentrate samples were premixed with varying proportions of graphite and additive. The mixtures were subjected to two different types of experiments: thermal analysis measurements and furnace tests as described in a previous publication by the lead authors (Sokhanvaran and Paktunc, 2017). The chemical compositions of ores from three different Ring of Fire deposits used in the experiments are shown in Table I, in comparison to various South African chromite ores used for benchmarking.

A comparison of the chemical compositions of the ores based on their potential reducibility (i.e. refractory/ nonrefractory ratio) (Slatter, 1980) reveals that South African ores are easier to reduce as they are less refractory. However, owing to the lower $\mathrm{Cr} / \mathrm{Fe}$ ratio of these ores, the grade of ferrochromium produced is lower than that potentially obtainable from the Canadian ores. The reducibility index initially developed by Barnes and Eric (1995) also predicted a lower reducibility index.

\section{Results and discussion}

\section{Reducibility of different ores}

The reducibility of three different chromite ores, based on TGA analysis, is shown in Figure 1. It is worth noting that, from a mineralogical perspective, the Canadian ore contains hydrous silicate gangue minerals. This is reflected in larger mass losses by the Black Thor and Black Horse ores during

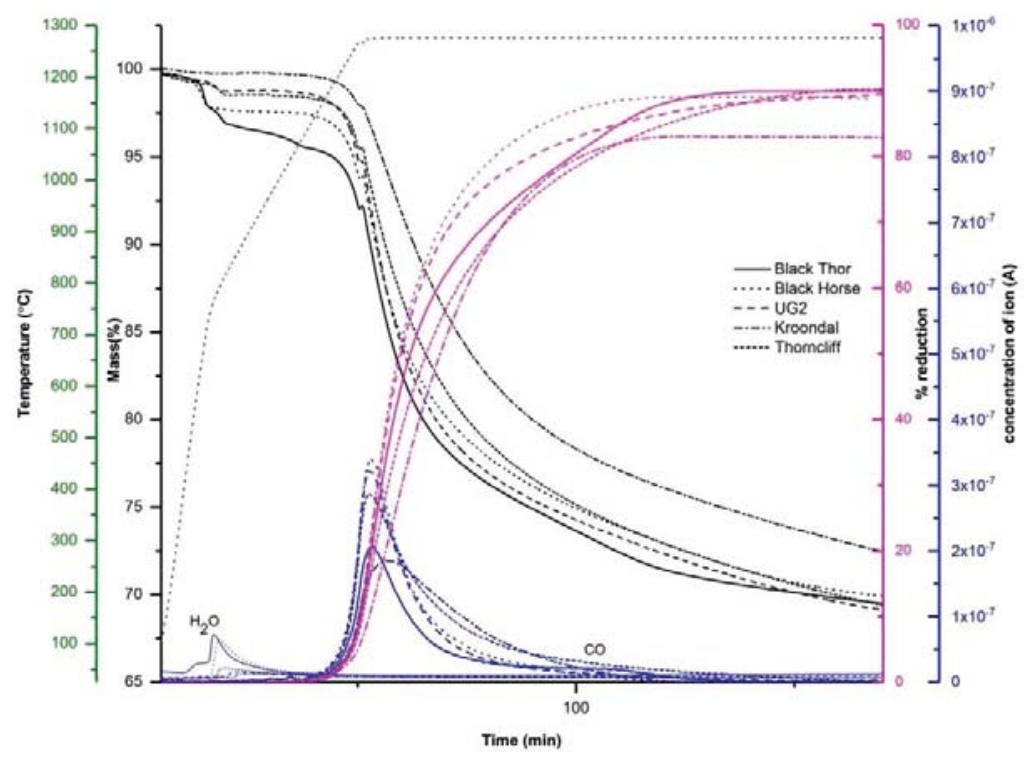

Figure 1-Thermogravimetric analysis (ore:graphite approx. 100:22) 


\section{NaOH-assisted direct reduction of Ring of Fire chromite ores}

the first stage of heating, associated with the $\mathrm{H}_{2} \mathrm{O}$ peak. To isolate the effect of dehydroxylation from the mass loss due to reduction, the purple curves illustrate the mass loss associated with reduction of each mixture containing $100 \mathrm{~g}$ of ore (the mass loss due to dehydroxylation was subtracted from the curve). This graph also illustrates that reduction starts in all of these cases at about the same temperature (above $1200^{\circ} \mathrm{C}$ ). The extent of reduction for all these ores seems to be similar considering the small difference in the amount of removable $\mathrm{O}_{2}$ from each ore (Table I). The UG2 achieved the highest degree of reduction, whereas the Black Thor ore has the lowest, as would be expected from the R: non- $\mathrm{R}$ ratio. This high ratio for Black Thor ore predicts a lower degree of reduction, and also a more sluggish reduction, as illustrated by the mass loss curve for this ore.

\section{Effect of $\mathrm{NaOH}$ on reducibility of Canadian and South African ores}

The effects of $\mathrm{NaOH}$ on the reduction of UG2 and Black Thor ores are similar, as shown in Figure 2. $\mathrm{NaOH}$ decreases the reduction temperature and increases the rate and degree of reduction. For both ores, the addition of $\mathrm{NaOH}$ results in three stages of mass loss and two major CO peaks. Although the total mass loss increased with the addition of $\mathrm{NaOH}$, it is difficult to confirm that $\mathrm{NaOH}$ addition results in a higher degree of reduction, due to the possible decomposition of $\mathrm{NaOH}$ and the presence of $\mathrm{Na}$ and $\mathrm{H}_{2}$ in the gas phase.

The first mass loss peak, which is associated with the water peak, is due to the evaporation of absorbed water from $\mathrm{NaOH}$. The intensity of water evolution from the Black Thor ore is greater than that observed in the case of UG2, which can be ascribed to the difference in the mineralogy of the two ores and dehydroxylation of the Black Thor ore during heating. As was explained previously (Sokhanvaran and Paktunc, 2017), the second stage of mass loss associated with the first $\mathrm{CO}$ peak is due to reaction between $\mathrm{NaOH}$ and $\mathrm{C}$, as well as the start of Fe reduction. This endotherm commences at $750^{\circ} \mathrm{C}$ in both cases, which shows the accelerating role of $\mathrm{NaOH}$ in Fe reduction. Assuming that the mass loss associated with the reaction of $\mathrm{NaOH}$ is the same in both samples (due to the identical masses of $\mathrm{NaOH}$ added), the larger mass loss observed for UG2 is probably due to the greater amount of $\mathrm{Fe}_{2} \mathrm{O}_{3}$ present in this ore.

The third stage of mass loss, also associated with a CO peak, can be explained as the mass loss due to the reduction of $\mathrm{Cr}$ and $\mathrm{Fe}$. Commencement of this reaction causes another endotherm on the DSC curve at $910^{\circ} \mathrm{C}$ for the Black Thor ore and $1000^{\circ} \mathrm{C}$ for $\mathrm{UG} 2$ ore. This reaction occurs at a faster rate above 1000 and $1075^{\circ} \mathrm{C}$, respectively, for these ores. The greater mass loss at this stage in the case of Black Thor ore can be explained by the higher concentration of $\mathrm{Cr}_{2} \mathrm{O}_{3}$ compared to UG2. As mentioned earlier, mass loss is not a sufficient indicator of the degree of reduction; in this case, however, the higher mass loss in the last stage compared to the total mass loss in the absence of the additive in both cases indicates that the reduction progresses to a higher degree in the presence of $\mathrm{NaOH}$.

The effect of $\mathrm{NaOH}$ on the direct reduction of chromite ore has been discussed elsewhere (Sokhanvaran and Paktunc 2018). This additive reacts with all reactants present in the mixture: ore, gangue, and carbon. The reaction of the octahedrally coordinated ions in chromite with $\mathrm{NaOH}$ forms $\mathrm{NaAlO}_{2}$ and $\mathrm{NaCrO}_{2}$, leaving behind the tetrahedrally coordinated cations as monoxide phases (i.e. $\mathrm{MgO}$ and $\mathrm{FeO}$ ). Destruction of the chromite crystal structure enhances the reduction mechanism. $\mathrm{NaOH}$ also reacts with the silicate gangue minerals to form a sodium aluminosilicate phase as a slag surrounding the original chromite particles. This slag phase is molten and provides a medium for transporting $\mathrm{Fe}$ and $\mathrm{Cr}$ ions to the reduction sites. $\mathrm{NaOH}$ also interacts with carbon, which results in the acceleration of the Boudouard reaction and generation of $\mathrm{CO}$ and $\mathrm{Na}$ vapour.

\section{Characterization of the reduction products}

As the TGA test results showed that the addition of $\mathrm{NaOH}$ to the feed mixture improves the reduction reaction, larger scale furnace tests were conducted to confirm the effectiveness of this additive on Black Horse ore. The chemical compositions of the two feeds are listed in Table II. The first sample contains less than the stoichiometric amount of carbon for complete metallization, and the second one contains just enough to remove oxygen from the reducible cations in the ore.

Both of these mixtures were heated to $1250^{\circ} \mathrm{C}$ for 1 hour. The SEM micrographs of the samples after reduction are shown in Figure 3.

The metallic phases in these micrographs are the hexagonal carbide (Figure $3 \mathrm{~b}$ ) and the coarse lumpy alloy (Figure 3d). The chemical compositions of the metallic phases forming in each sample are plotted in Figure 4. As illustrated, the concentration of $\mathrm{Cr}$ in the metallic phase of sample A1 is lower than in sample A2. This confirms that $\mathrm{Cr}$ reduction was not complete in A1, due to the carbon deficiency. The higher concentration of $\mathrm{Cr}$ in the metallic phase of sample A2 as well

Table I

\section{Composition of chromite ores}

\begin{tabular}{|c|c|c|c|c|c|c|c|c|}
\hline Ore $(75-106 \mu \mathrm{m})$ & $\mathrm{Cr} / \mathrm{Fe}$ (mole ratio) & $\mathrm{Cr}_{2} \mathrm{O}_{3}(\mathrm{wt} \%)$ & $\mathrm{Fe}_{2} \mathrm{O}_{3}(\mathrm{wt} \%)$ & MgO (wt \%) & $\mathrm{Al}_{2} \mathrm{O}_{3}(\mathrm{wt} \%)$ & $\mathrm{SiO}_{2}$ (wt $\%$ ) & R:non-R (by mass) & Removable $\mathrm{O}_{2}(\mathrm{wt} \%)$ \\
\hline Black Thor & 1.97 & 43.11 & 21.40 & 13.60 & 13.50 & 5.67 & 2.50 & 20.0 \\
\hline Black Horse & 2.1 & 46.92 & 23.02 & 12.00 & 13.20 & 4.24 & 2.64 & 21.7 \\
\hline Black Bird conc. & 2.1 & 47.32 & 24.10 & 10.20 & 12.55 & 3.09 & 2.58 & 22.2 \\
\hline UG2 & 1.3 & 41.57 & 33.09 & 10.13 & 15.68 & 3.01 & 1.87 & 23.1 \\
\hline Kroondal & 1.5 & 44.17 & 30.18 & 10.05 & 15.22 & 2.79 & 2.10 & 23.0 \\
\hline Thorncliff & 1.5 & 43.07 & 29.47 & 10.23 & 14.87 & 3.28 & 2.10 & 22.5 \\
\hline
\end{tabular}




\section{Na0H-assisted direct reduction of Ring of Fire chromite ores}

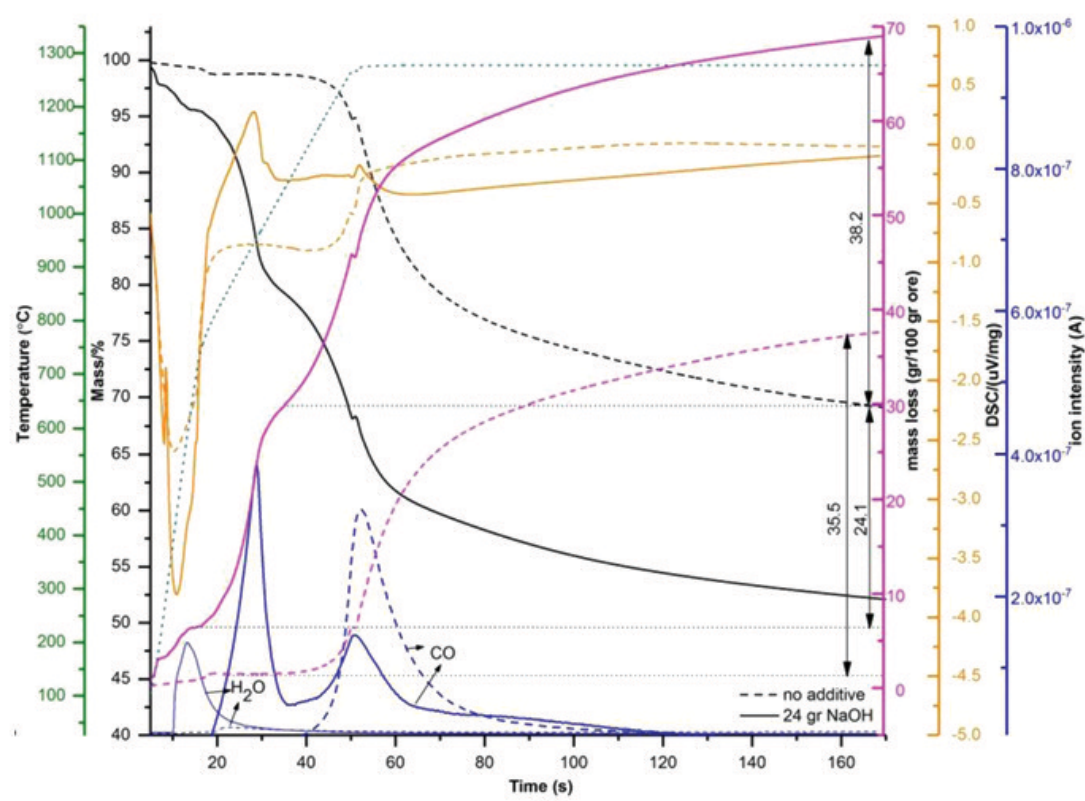

(a)

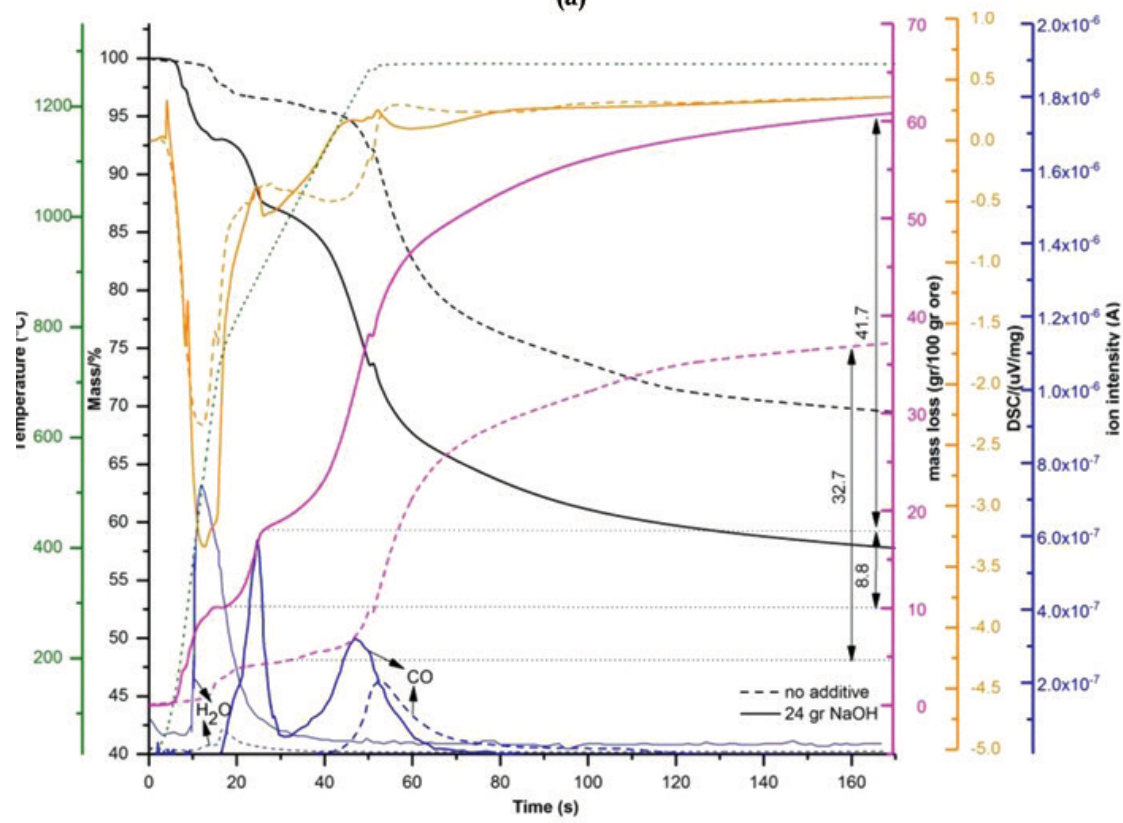

(b)

Figure 2-Effect of $\mathrm{NaOH}$ addition on reducibility (ore: graphite: $\mathrm{NaOH}$ approx. 100: 22: 24); (a) UG2, (b) Black Thor

\section{Table II}

\section{Composition of the mixture used for the initial large-scale test by KWG}

\begin{tabular}{|l|c|c|c|c|c|}
\hline & Ore (g) & $\mathbf{C}(\mathbf{g})$ & NaOH (g) & Temp ( $\left.{ }^{\circ} \mathbf{C}\right)$ & Weight loss (\%) \\
\hline A-1 & 100 & 11.0 & 6.1 & 1250 & 9.7 \\
A-2 & 100 & 17.6 & 6.5 & 1250 & 15 \\
\hline
\end{tabular}

as large particle size of the alloy (Figures $3 \mathrm{c}$ and $3 \mathrm{~d}$ ) confirms that a higher degree of reduction was achieved in this sample, consistent with thermochemical theory.

The large particle size of the alloy provides an opportunity for subsequent physical separation of the metallic phase from the residual phases in the sample. The result of gravity separation by simple superpanning is shown in Figure 5, which illustrates the potential of this technique for separation of a marketable metallic product. However, further work is needed to investigate the factors influencing the morphology and degree of reduction, as well as the relationship between product grade and recovery.

CanmetMINING conducted further investigations on ore and concentrate samples from the Ring of Fire deposits. For this study, $100 \mathrm{~g}$ of the Black Thor ore and Black Bird concentrate were each mixed with $22 \mathrm{~g}$ of graphite, both with and without $\mathrm{NaOH}(12 \mathrm{~g})$. The mixtures were reduced at $1300^{\circ} \mathrm{C}$ for 1 hour. The mass loss was normalized for a mixture containing $100 \mathrm{~g}$ of ore in all cases for comparison. The mass losses from the reduction of the Black Thor 


\section{NaOH-assisted direct reduction of Ring of Fire chromite ores}

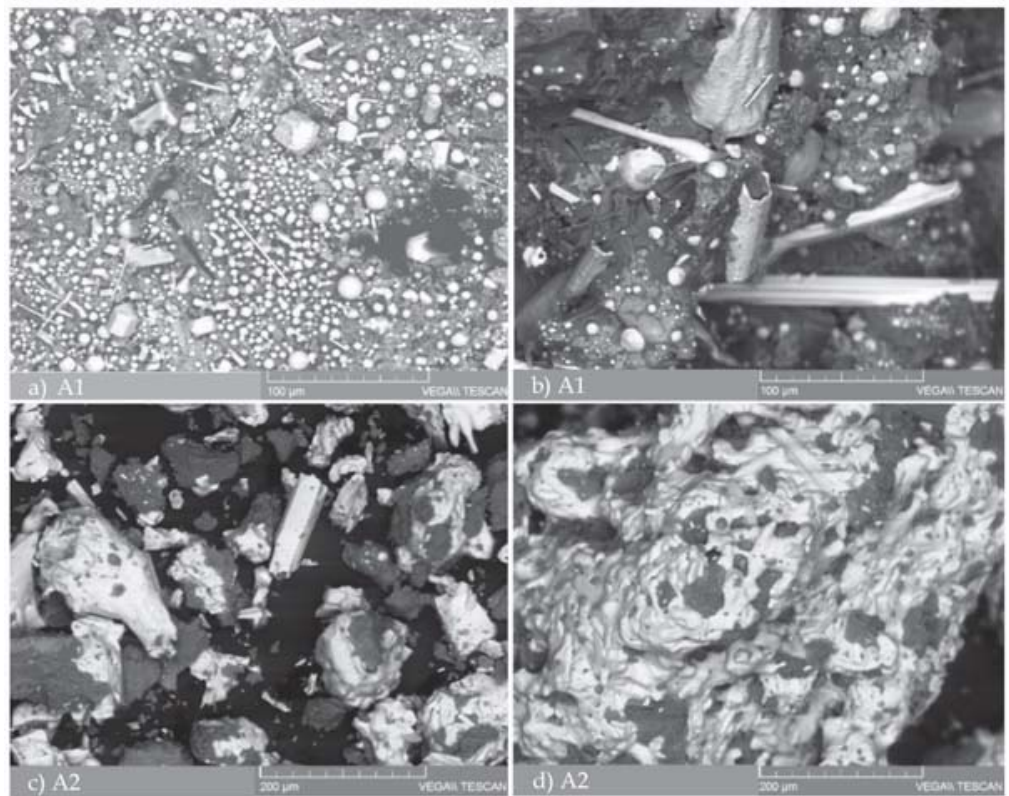

Figure 3-Micrographs of samples after reduction at $1250^{\circ} \mathrm{C}$ for 1 hour. (a, b) sample $\mathrm{A} 1$; (c, d) sample A2

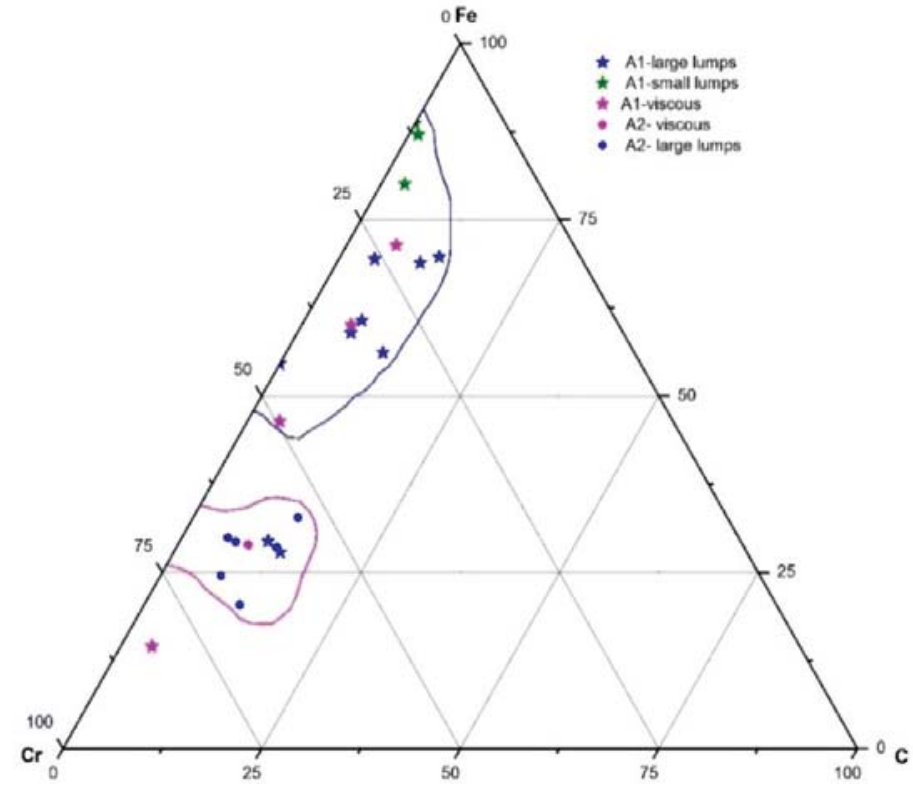

Figure 4-Chemical compositions of metallic phases formed in samples A1 and A2

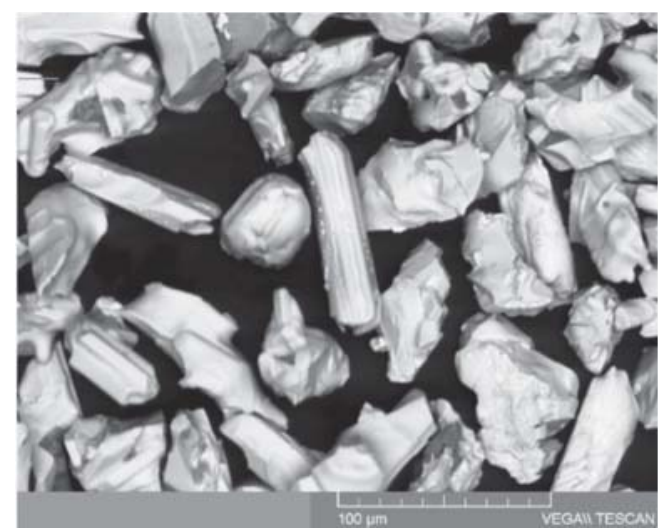

Figure 5-Metallic products concentrated by superpanning of combined A1 and A2 products from direct reduction of ore with $\mathrm{NaOH}$ 


\section{Na0H-assisted direct reduction of Ring of Fire chromite ores}

samples were $24.8 \mathrm{~g}$ without $\mathrm{NaOH}$ and $38 \mathrm{~g}$ in the presence of $\mathrm{NaOH}$. The mass losses for Black Bird samples, which were both subjected to 2 hours' reduction, were 29.4 and 43.2 g, respectively. The mass losses for both ore and concentrate increased with the addition of $\mathrm{NaOH}$. The micrographs of the samples are shown in Figure 6. Higher degrees of reduction as a result of $\mathrm{NaOH}$ addition are obvious in both cases. The degree of $\mathrm{Cr}$ metallization measured by the XAFS method for sample (c) is $38.4 \%$, and $85.5 \%$ for

sample $(d)$.

Changes in the morphology of both the metallic and residual chromite particles were observed with the $\mathrm{NaOH}$ addition. The metallic phases formed mainly inside the chromite particles without much metallization around the graphite and chromite particles as was the case in the absence of $\mathrm{NaOH}$, implying the involvement of $\mathrm{CO}$ in the reduction. The chemical compositions of the alloy phase formed in each of these samples, as well as the chemical composition of the residual chromite, are shown in Figure 7.

The increase in $\mathrm{Cr}$ content of the alloy phase (Figure $7 \mathrm{a}$ ) for the Black Thor samples clearly illustrates the enhancement of reduction as a result of $\mathrm{NaOH}$ addition. This improvement is illustrated in Figure $7 \mathrm{~b}$ by the decrease in the Cr plus $\mathrm{Fe}$ contents and increase in the $\mathrm{Mg}$ plus $\mathrm{Al}$ contents of the residual chromite. This change in chemical composition is less obvious in samples containing Black Bird concentrate as the reduction in this sample was significant even without $\mathrm{NaOH}$, due to the longer residence time. However, the total degree of metallization increased dramatically, as shown in Figures $6 \mathrm{a}$ and $6 \mathrm{~b}$.

The alloy particles formed with $6 \mathrm{~g} \mathrm{NaOH}$ addition were larger than those with $12 \mathrm{~g} \mathrm{NaOH}$. This may indicate that although a higher $\mathrm{NaOH}$ concentration may be beneficial in terms of improving the degree of reduction (Sokhanvaran and Paktunc, 2017), it may have an adverse effect on crystal nucleation by accelerating the rate of $\mathrm{CO}$ generation (the first $\mathrm{CO}$ peak in Figure 2). The optimum condition that results in both a high degree of reduction and large alloy particles lies somewhere between these two levels, and requires further investigation.

\section{Implications for processing}

Barnes, Muinonen, and Lavigne (2015) discussed the broader techno-economic implications of a process that could take advantage of the improved kinetics and lower operating temperature, but without a specific process configuration in mind. An early Metsim model, based loosely on the Premus kiln process, provided provisional mass and energy balance data used for a high-level look at the carbon footprint implications. The high gas volume generated using reformed natural gas in a vertical shaft reactor such as in the Midrex process was considered impractical and the focus on reactor type moved toward rotary or linear hearth furnaces. Early in 2017, the possibility of utilizing the Envirosteel concept was raised and Erasmus (private communication) performed some preliminary calculations based on UG2 chromite reduction which showed that the reverberatory nature of the ESS furnace configuration allowed much better energy utilization while still maintaining reducing conditions in the bed.

Subsequent modelling on Ring of Fire ore containing six units $\mathrm{NaOH}$ addition to 100 units of ore has confirmed the initial conclusions. In this model, combustion of the CO-rich off-gas in the freeboard region of the reactor provides sufficient energy to raise the internal temperature to $1400^{\circ} \mathrm{C}$ and sufficient surplus heat to sustain the endothermic reduction reactions at $1250^{\circ} \mathrm{C}$ (calculated in the modelling to be $2.03 \mathrm{MWh}$ per ton $\mathrm{FeCr}$ alloy produced).

From a process efficiency perspective, the kinetics of the last $15 \%$ of metallization is extremely sluggish and this has been recognized by Glencore in their Premus operations. The operating conditions for a commercial process would therefore logically target $80-85 \%$ metallization, and apparently be 'undercoked' from a stoichiometric perspective.

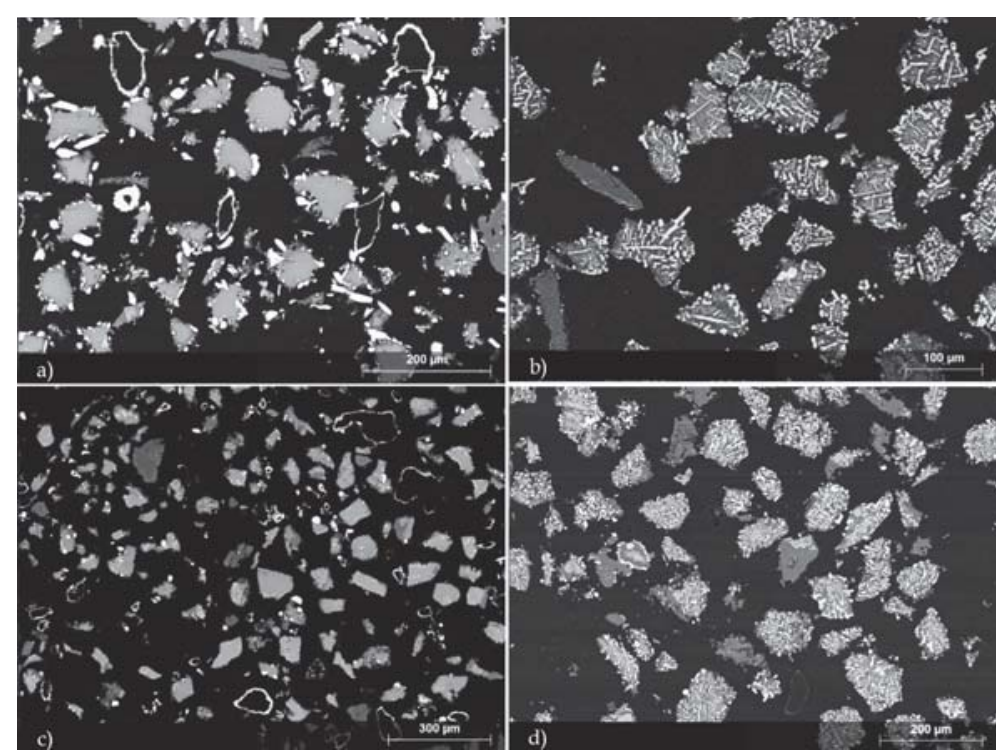

Figure 6-SEM micrographs of sample cross-sections after reduction at $1300^{\circ} \mathrm{C}$. (a) Black Bird concentrate: graphite $=100: 22$, reduced for $2 \mathrm{~h}$; (b) Black Bird concentrate: graphite: $\mathrm{NaOH}=100: 22: 12$, reduced for 2 h; (c) Black Thor ore: graphite = 100:22, reduced for 1 h; (d) Black Thor ore: graphite: NaOH = 100:22:12, reduced for $1 \mathrm{~h}$ 


\section{NaOH-assisted direct reduction of Ring of Fire chromite ores}

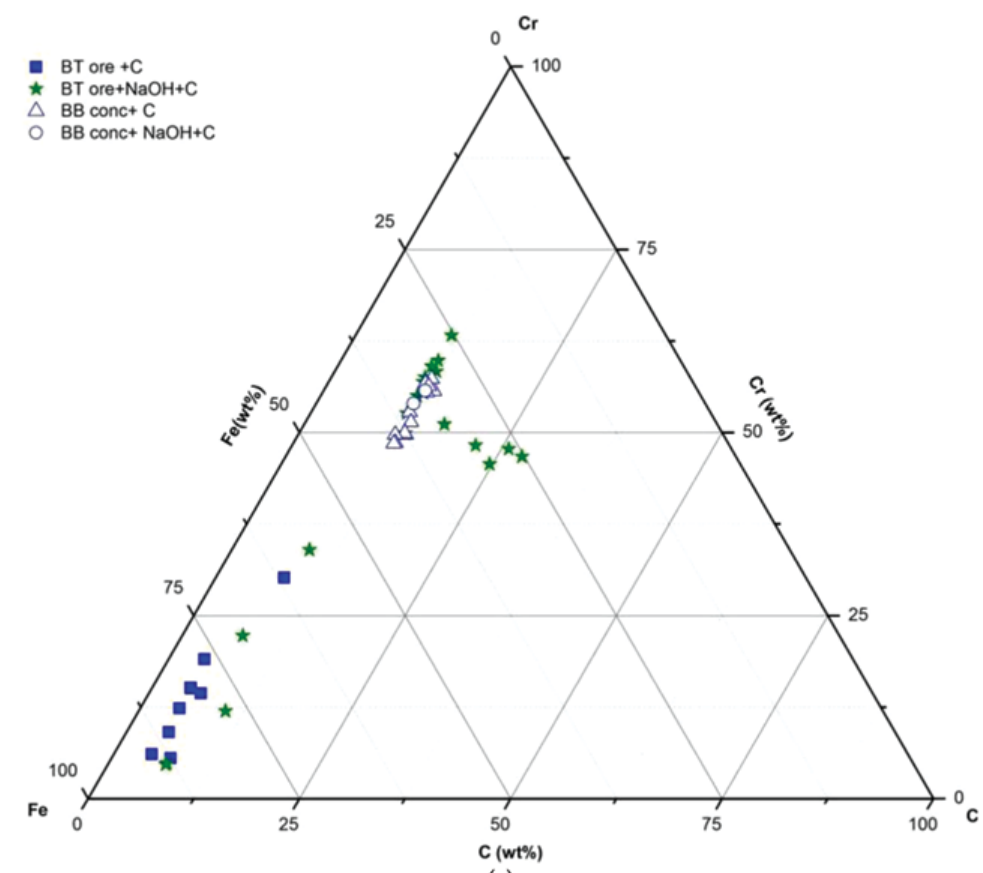

(a)

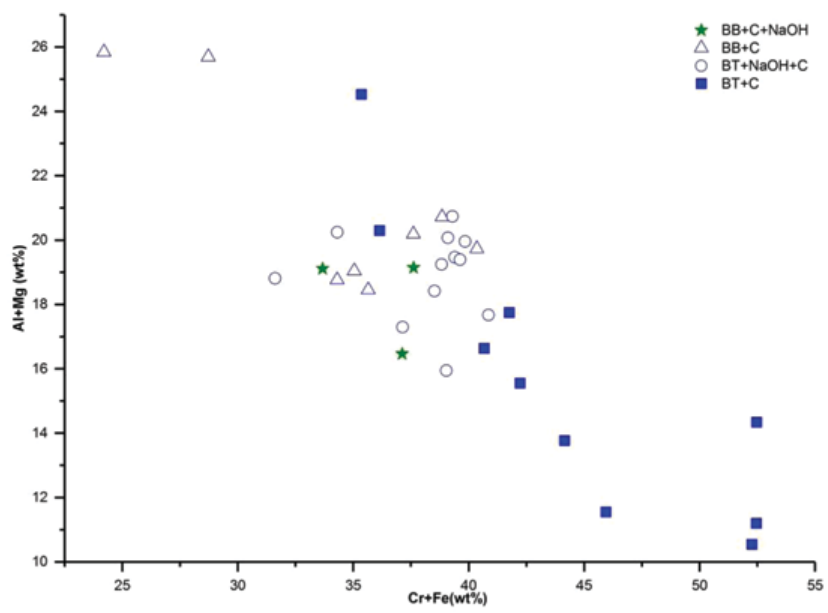

(b)

Figure 7-Chemical compositions of phases formed in Figure 6; (a) alloy phases, (b) residual chromite

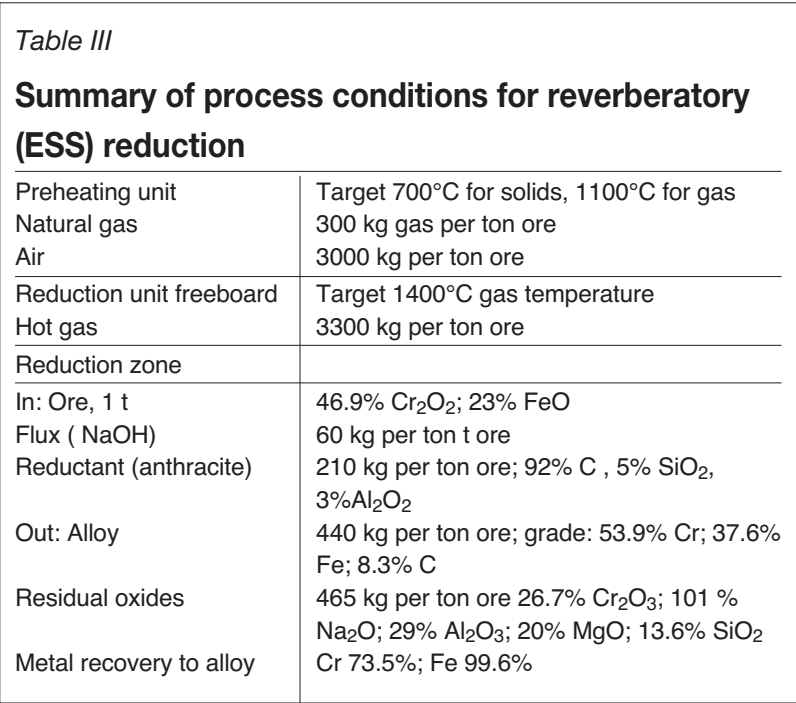

Since Rankin's work (Rankin and Finn, 1978; Rankin, 1979) had shown conclusively that indirect reduction of chromium oxides in chromite is indeed possible at high partial pressure of $\mathrm{CO}$, where $\mathrm{CO}$ is regenerated via the Boudouard reaction with solid carbon in the vicinity, and indirect reduction of iron oxides contributes to the overall reduction, slightly more metallization is obtained than would be calculated by assuming only direct reduction via carbon. The alkali salt catalyses the $\mathrm{CO}$ regeneration and improves the kinetics of the important gaseous reduction reaction.

As noted in the experimental results, a lower degree of $\mathrm{Cr}$ metallization would be acceptable as it is consistent with the economic argument by Kleynhans et al., (2017) on the financial benefits to be gained by preoxidation of chromite prior to reduction, for maximizing unit throughput. Similarly, smaller reactors, with higher specific throughput and lower unit capital cost, maximize the benefits to be derived from the enhanced reaction kinetics using $\mathrm{NaOH}$. 


\section{Na0H-assisted direct reduction of Ring of Fire chromite ores}

\section{Discussion and conclusion}

Laboratory work has consistently confirmed the catalytic action of small amounts of caustic soda on the reduction kinetics of Canadian chromite. The ability of caustic soda to destruct the chromite spinel structure in the absence of a reductant, the 'buffering' influence of the sodium on the Boudouard reaction, and the presence of a small amount of slag above $720^{\circ} \mathrm{C}$ would contribute synergistically to the efficiency of the overall reduction reactions.

Capitalizing on these benefits does, however, require considerably more work at larger scale since the major challenges are related to reactor design. It is recognized that conversion of promising laboratory-scale test work to a viable commercial processes is a long and arduous process. Currently, the scarcity of sufficient Canadian ore for test work is one of the impediments to progressing this promising route.

It is worth pointing out that the greatest value in the prereduction option will likely be the ability to treat fines and concentrates generated during the mining and processing of the high-grade massive ores, since the Ring of Fire ores are competent, and the mining and transportation costs for these ores are significant. Until detailed mining plans are developed, speculation over the role that prereduction will play in the commercial exploitation of the Ring of Fire is premature.

\section{Acknowledgements}

This research is funded by Natural Resources Canada's Rare Earth and Chromite R\&D programme. Contributions of the following are acknowledged: Judith Price for polished section preparation, KWG Resources for providing ore samples, and XPS for performing the furnace tests and TGA-DSC analyses. $\mathrm{X}$-ray absorption spectroscopy experiments were performed at the PNC-CAT beamline, Advanced Photon Source, Argonne National Laboratory, which is supported by the US Department of Energy under Contracts W-31-109-Eng-38 (APS) and DE-FG03-97ER45628 (PNC-CAT) through a General User Proposal to one of the lead authors (DP) and a Partnership Proposal funded by the Natural Sciences and Engineering Research Council of Canada through a major facilities access grant to the Canadian Light Source.

\section{References}

BARNES, A.R. and ERIC, R.H. 1995. The relative reducibilities of chromite ores and relative reactivity of carbonaceous reductants. Proceedings of INFACON VII, Trondheim, Norway, 11-14 June 1995. Tveit, H., Tuset, J.K., and Page, I.G. (eds.). Norwegian Ferroalloy Producers Research Organization (FFF).

Barnes, A.R., Finn, C.W.P., and Algie, S.H. 1983. The prereduction and smelting of chromite concentrate of low chromium-to-iron ratio. Journal of the South African Institute of Mining and Metallurgy, vol. 83, no. 3. pp. 49-54.

Barnes, A.R., Muinonen, M., and Lavigne, M. J. 2015. Reducing energy consumption by alternative processing routes to produce ferrochromium alloys from chromite ore. Proceedings of COM 2015. The Metallurgical Society of CIM. pp. 1-22.

BisaKa, K., MaKWARELA, M.O., and Erwee1, M.W. 2016. Solid-state reduction of South African manganese and chromite ores. Proceedings of the XXVIII International Mineral Processing Congress (IMPC 2016), Québec City, 11-15 September 2016. pp. 1-16.

CRAMER, M. 2016. Review and analysis of international experiences in chromite mining and ferrochrome production, and implications for the development of Canadian deposits. Unpublished Technical Report, CanmetMINING, Natural Resources Canada.
DaWSON, N.F. and EDWARDS, R.I. 1986. Factors affecting the reduction rate of chromite. Proceedings of INFACON N, Rio de Janeiro, Brazil, 31 August 3 September, 1986. Associação Brasileira dos Produtores de Ferro-LigasAbrafe. pp. 105-113.

DinG, Y. L.1997. Catalytic reduction of carbon-chromite composite pellets by lime. Thermochimica Acta, vol. 292. pp. 85-94.

DinG, Y.L. and WARNER, N.A. 1997. Reduction of carbon-chromite composite pellets with silica fluxes. Ironmaking and Steelmaking, vol. 24, no. 4. p. 283.

Katayama, H.G., ToKuda, M., and Ohtani, M. 1985. Promotion of the carbothermic reduction of chromite ore by the addition of borates. Tetsuto-Hagané, vol. 72, no. 10. pp. 1513-1520. https://doi.org/10.2355/tetsutohagane1955.72.10_1513

Kelly, T.D. and MATOS, G.R. 2014. Historical statistics for mineral and material commodities in the United States. https://minerals.usgs.gov/minerals/pubs/historical.

KLeynhans, E.L.J., BeuKes, J.P., van ZyL, P.G., and Fick, J.I.J. 2017. Technoeconomic feasibility of a preoxidation process to enhance prereduction of chromite. Journal of the Southern African Institute of Mining and Metallurgy, vol. 117, no. 5. pp. 457-468. doi: 10.17159/24119717/2017/v117n5a8

LeKATOU, A. and WALKER, D. 1997. Effect of silica on the carbothermic reduction of chromite. Ironmaking \& Steelmaking, vol. 24, no. 6. p. 133

LI, J., BAI, G., and LI, G. 2011. Solid-state reduction properties of carbonbearing chromite pellets. Chinese Journal of Non Ferrous Metals, vol. 21, no. 5. pp. 1159-1164.

LI, G., LI., J., RAO, M., BAI, G., and JIANG, T. 2011 Reduction of carbon-burdened chromite pellets. Proceedings of the 2nd International Symposium on High Temperature Metallurgical Processes. Wiley. pp. 245-253.

Lu, W.K. 2012. Process of the production and refining of low-carbon DRI (direct reduced iron). US patent application $\mathrm{WO}_{2} 012149635 \mathrm{~A} 1$. http://google.com/patents/ $\mathrm{WO}_{2} 012149635 \mathrm{~A} 1$ ? cl=ko

Naiker, 0. 2006. The development and advantages of Xstrata's Premus Process. Proceedings of INFACON IX, Quebec City, Canada, 3-6 June 2001 pp. 112-119.

Neizel, B.W., Beukes, J.P., van ZyL, P.G., and Dawson, N.F. 2013. Why is $\mathrm{CaCO}_{3}$ not used as an additive in the pelletised chromite pre-reduction process? Minerals Engineering, vol. 45. pp. 115-120. doi: 10.1016/j.mineng.2013.02.015

NeuschutZ, D., Jan En, P., Friedrich, G., and Wiechowski, A. 1995. Effect of flux addition on the kinetics of chromite ore reduction with carbon. Proceedings of INFACON VII, Trondheim, Norway, 11-14 June 1995., Tveit, H., Tuset, J.K., and Page, I.G. (eds.). Norwegian Ferroalloy Producers Research Organization (FFF). pp. 371-382.

RANKIN, W.J. 1979. The composition and structure of chromite during reduction with carbon. Archiv für das Eisenhuttenwesen, vol. 50, no. 9. pp. 373-378.

RANKIN, W.J. and FinN, C.W. 1978. Solid state reduction by graphite and carbon monoxide of chromite from the Bushveld Complex. Mintek, Randburg, South Africa.

SLATTER, D. 1980. The chromium resources of Zimbawe. Institute of Mining Research. University of Zimbabwe.

SoKHAnVARAn, S. and PaKtunc, D. 2018. Effect of $\mathrm{NaOH}$ addition on the direct reduction of chromite ore: I: the mechanism. [in preparation].

SoKhanvaran, S. and Paktunc, D. 2017. The effect of fluxing agent on direct reduction of chromite ore. Proceedings of COM 2017. Canadian Institute of Mining, Metallurgy and Petroleum, Vancouver:

Sundar MurTi, N.S., Shah, K., GAdgeEl, V.L., and SeShadri, V. 1983. Effect of lime addition on rate of reduction of chromite by graphite. Transactions of the Institution of Mining and Metallurgy, vol. 92. pp. C172-C174.

UGWUEGBU, C. 2012. Technology innovations in the smelting of chromite ore. Innovative Systems Design and Engineering, vol. 3, no. 12. pp. 48-55.

VAN Deventer, J.S.J. 1988. The effect of additives on the reduction of chromite by graphite. Thermochimica Acta, 127, pp. 25-35.

WANG, Y., WANG, L., and CHOU, K.C. 2015. Effects of $\mathrm{CaO}, \mathrm{MgO} \mathrm{Al}_{2} \mathrm{O}_{3}$ and $\mathrm{SiO}_{2}$ on the carbothermic reduction of synthetic $\mathrm{FeCr}_{2} \mathrm{O}_{4}$. Journal of Mining and Metallurgy Section B: Metallurgy, vol. 51, no. 1. pp. 17-24. doi: 10.2298/JMMB140625024W

WEBER, P. and ERIC, R.H. 2006. The reduction of chromite in the presence of silica flux. Minerals Engineering, vol. 19. pp. 318-324. doi: 10.1016/j.mineng.2005.07.010

WiNTER, F. 2015. Production of chromium iron alloys directly from chromite ores. US patent US2016/0244864 A1. 